Journal of Accidents and Emergency Medicine 1995

12, 187-188

\title{
A tide of change in the management of an old fracture?
}

\author{
J.M. KENDALL, ${ }^{1}$ P.E. ALLEN ${ }^{2} \&$ S.E. MCCABE 1
}

'Accident And Emergency Department and ²Orthopaedic Department, Gloucester Royal Hospital, Gloucester, UK

\section{SUMMARY}

Colles' fractures are manipulated under a variety of anaesthetic techniques. An increasing awareness of cost and time within the National Health Service contributes to a marked change in the anaesthetic management of Colles' fractures. This paper presents the results of a survey of the anaesthetic techniques used in the larger accident and emergency (A\&E) departments of the UK, and demonstrates the increasing popularity of the haematoma block compared with 5 years ago $(7 \%$ in 1989 vs. $33 \%$ in 1994), at the expense of the general anaesthetic ( $44 \%$ in 1989 vs. $24 \%$ in 1994 ). The popularity of the Bier's block has remained unchanged (33\% in 1989 and 1994). Local and regional anaesthetic techniques can be safely performed by A\&E doctors, with appropriate monitoring, and this has beneficial resource implications for the anaesthetic department and the hospital.

Keywords: Bier's block, Colles' fracture, general anaesthetic, haematoma block

\section{INTRODUCTION}

Colles fractures of the distal radius are currently manipulated using a variety of anaesthetic methods in A\&E departments. A survey in 1989 by Hunter et al. ${ }^{1}$ revealed that formal general anaesthetic was the most popular method of anaesthesia used ( $44 \%$ of departments surveyed), followed by Bier's block (33\%), intravenous sedation $(13 \%)$ and haematoma block $(7 \%)$.

Cost and time are ever increasing concerns in the National Health Service and, assuming that it can be safely performed, a local anaesthetic will save both resources compared with a general anaesthetic.

Against this background, the haematoma block seems to have gained in popularity over the last few years. This paper demonstrates the changing anaesthetic management of Colles' fracture manipulation over the last 5 years.

\section{PATIENTS AND METHODS}

A total of 150 A\&E departments seeing over 35000 patients annually were sent a postal questionnaire in April 1994, requesting details of the methods of anaesthesia used in the manipulation of Colles' fractures.

\section{RESULTS}

A total of 86 replies were received (a $58 \%$ response rate). Table 1 shows the preferred method of

Table 1. Preferred method of anaesthesia now used, compared to that used in 1989

\begin{tabular}{|c|c|c|c|c|c|c|c|}
\hline \multirow[b]{2}{*}{ Type of anaesthetic } & \multicolumn{2}{|c|}{$\begin{array}{c}\text { Preferred } \\
\text { method (\%) }\end{array}$} & \multicolumn{2}{|c|}{ Performed } & \multirow{2}{*}{$\begin{array}{c}\text { Fasted } \\
(\%)\end{array}$} & \multirow{2}{*}{$\begin{array}{l}\text { Admitted } \\
(\%)\end{array}$} & \multirow{2}{*}{$\begin{array}{c}\text { Monitored } \\
(\%)\end{array}$} \\
\hline & 1989 & 1994 & Anaesthetist & A\&E doctor & & & \\
\hline General anaesthetic & 44 & 24 & 100 & 0 & 100 & 66 & 100 \\
\hline Bier's block & 33 & 33 & 46 & 54 & 60 & 0 & 85 \\
\hline Haematoma block & 7 & 33 & 0 & 100 & 0 & 0 & 33 \\
\hline Intravenous benzodiazepine & 13 & 7 & 0 & 100 & 46 & 0 & 100 \\
\hline
\end{tabular}

Correspondence:

J.M. Kendall, Registrar, Accident and Emergency Department, Frenchay Hospital, Frenchay Park Road, Bristol, BS16 1LE, UK 
anaesthesia now used compared with that used in 1989.

It is interesting to note that the majority of departments $(78 \%)$ now use a variety of techniques. There is a marked trend away from general anaesthesia towards local anaesthesia, with a large increase in the number of haematoma blocks (33\%), at the expense of the general anaesthetic (24\%), with regional anaesthesia (Bier's block) remaining unchanged in popularity $(33 \%)$. There has been a reduction in the involvement of anaesthetists in the management of Colles' fractures, reflected both in the decreased number of general anaesthetics being performed ( $24 \%$ vs. $44 \%, P<0.01$ by Chi-squared analysis) and in the decreased number of anaesthetic staff administering regional anaesthesia.

Lower numbers of general anaesthetics have resulted in reduced numbers of patients being fasted in A\&E departments and/or requiring admission.

Monitoring (ECG, blood pressure and oxygen saturation) is used universally in general anaesthesia, in $85 \%$ of Bier's blocks, and in $33 \%$ of haematoma blocks.

\section{DISCUSSION}

More efficient patient flow through the A\&E department, reduced delays, and a reduction in the need for admission have considerable resource implications, and may well be the promoting factors in a tide of change in the anaesthetic management of Colles' fractures towards local anaesthesia at the expense of general anaesthesia.

The haematoma block has increased considerably in popularity over the last 5 years $(7 \%$ vs. $33 \%$; $P<0.006$ by Chi-squared analysis). It is simply and rapidly performed and does not require the presence of an anaesthetist. It has been argued that pain relief is inferior, ${ }^{2}$ and technically it converts a closed fracture into an open fracture. No reports of fracture site infection have been published.

Overall complication rates of the various anaesthetic techniques were very low; recurrent complaints were of delay whenever anaesthetists were involved, cuff pain in patients having a Bier's block, and 'breakthrough' pain in patients having a haematoma block.
One death was reported in the Bier's block group in 1983 from tourniquet failure whilst using Bupivicaine. Since then, however, new guidelines have been introduced, and Prilocaine is now used exclusively, with no significant adverse effects reported. ${ }^{3,4}$ One respiratory arrest was reported in a patient receiving intravenous sedation with a haematoma block, and one respiratory arrest in a patient receiving intravenous sedation alone.

All the methods used have good safety records with few adverse events recorded, but universally available monitoring equipment must be used. There is cause for concern with regard to levels of monitoring in haematoma blocks. Although this is a local anaesthetic technique, significant levels of systemic Lignocaine have been documented. ${ }^{5}$ The technique should therefore be performed with the same degree of caution and monitoring as that used for a Bier's block.

Regional and local anaesthesia are emerging as the most popular techniques in practice, each accounting for $33 \%$ of preferred methods in use today. There are few reports in the literature comparing the two methods in terms of pain perception, patient flow through the department, functional outcome, etc., and such data are needed before one method can be recommended in preference to another. Accordingly, a study examining these issues is now in progress in several centres locally.

\section{REFERENCES}

1. Hunter J.B., Scott M.J. \& Harries S.A. (1989) Methods of anaesthesia used for reduction of Colles' fractures. British Medical Journal 299, 1316-1317.

2. Wardrope J. et al. (1985) Comparison of local anaesthetic techniques in the reduction of Colles' fracture. Archives of Emergency Medicine 2, 67-72.

3. Bartholomew K. \& Sloan J.P. (1990) Prilocaine for Bier's block: how safe is safe? Archives of Emergency Medicine 7, 189-195.

4. Brown E.M., McGriff J.T. \& Malinowski R.W. (1989) Intravenous regional anaesthesia (Bier's block): review of 20 years experience. Canadian Journal of Anaesthesiology 36, 307-310.

5. Quinton D.N. (1988) Local anaesthetic toxicity of haematoma blocks in the manipulation of Colles' fractures. Injury 19, 239-240. 